\title{
NOVAS ESPÉCIES DE LAMIINAE (COLEOPTERA, CERAMBYCIDAE) NEOTROPICAIS
}

\author{
Maria Helena M. Galileo ${ }^{1}$ \\ Ubirajara R. Martins ${ }^{2}$
}

\begin{abstract}
NEW SPECIES OF NEOTROPICAL LAMIINAE (COLEOPTERA, CERAMBYCIDAE). Nine species are described: Xenofreini, Xenofrea fulgida from Amazonas, X. albofasciata from Paraná and Santa Catarina; Hemilophini, Sphallonycha irundisa from Amazonas, Apagomerina apicalis from Santa Catarina, Isomerida paraba from Amazonas, all from Brazil; I. santamarta from Magdalena, Colombia; Canarana exotica from Pichincha, Equador; Falsamblestiini, Nyctonympha carioca from Rio de Janeiro, Brazil; Calliini, Euryestola castanea from Amazonas, Brazil.
\end{abstract}

KEYWORDS. Callini, Falsamblestiini, Hemilophini, Neotropical, Xenofreini.

\section{INTRODUÇÃO}

Dentre o material recebido para estudo oriundo de diversas instituições, detectaramse espécies novas que pertencem às tribos Xenofreini, Hemilophini, Falsamblesthiini e Calliini. A tribo Xenofreini, ainda pouco estudada, reunia, até recentemente, sete espécies distribuídas em dois gêneros (MonNÉ, 1994). GALILEO \& MARTINS (1999) estabeleceram dois gêneros monotípicos e uma espécie de Xenofrea Bates, 1885, além de chave para o reconhecimento dos gêneros. Com relação aos Lamiinae com garras tarsais bífidas ou apendiculadas, os gêneros Nyctonympha Thomson, 1868 (Falsamblesthiini), Apagomerina Gilmour, 1962 (Hemilophini) e Euryestola (Calliini) foram revisados com chaves para as respectivas espécies (Martins \& Galileo, 1992, 1996; Galileo \& Martins, 1997).

Objetiva-se descrever as espécies novas, especialmente aquelas cujos espécimens foram coligidos por aspersão de inseticida em copas de árvores da Amazônia.

1. Museu de Ciências Naturais, Fundação Zoobotânica do Rio Grande do Sul, Caixa Postal 1188; Porto Alegre RS, 90001-970, Brasil.

2. Museu de Zoologia, Universidade de São Paulo, Caixa Postal 42594, São Paulo SP, 04299-970, Brasil. 
As dimensões são dadas em milímetros. As siglas mencionadas ao longo do texto são: CMNO, Canadian Museum of Nature, Ottawa; CMNH, Carnegie Museum of Natural History, Pittsburgh; INPA, Instituto Nacional de Pesquisas da Amazônia, Manaus; MCNZ, Museu de Ciências Naturais, Fundação Zoobotânica do Rio Grande do Sul, Porto Alegre; MZSP, Museu de Zoologia, Universidade de São Paulo, São Paulo.

\title{
Xenofreini \\ Xenofrea fulgida sp. nov.
}

(Fig. 1)

\begin{abstract}
Etimologia. Latim, fulgidus = brilhante; alusivo ao brilho acentuado do tegumento dos élitros.
\end{abstract}

Tegumento castanho-escuro, pouco mais avermelhado no protórax e na face ventral, com ligeiro reflexo metálico nos élitros. Fronte com pubescência esbranquiçada e alongada. Sutura coronal bem-marcada entre as bases dos tubérculos anteníferos e prolongada até o occipício. Tubérculos anteníferos distantes e apenas projetados. Lobos oculares superiores pouco mais afastados entre si que a largura de um lobo. Lobos oculares inferiores mais curtos que as genas. Comprimento das antenas pouco maior do que o do corpo. Escapo subcilíndrico, levemente engrossado para a extremidade e subigual em comprimento ao antenômero III. Antenômero IV subigual em comprimento ao III, mais longo que os seguintes. Antenômeros V-X com comprimentos subiguais; o XI mais curto que o X. Pubescência antenal rala, mais concentrada e esbranquiçada no terço basal do antenômero IV. Protórax mais largo do que longo. Pronoto levemente convexo, sem gibosidade. Lados do protórax com acentuada elevação transversal acima das procoxas e gibosidade arredondada pouco atrás do meio. Pubescência pronotal branco-rósea, escamiforme ( $40 \mathrm{x}$ ), não oblitera totalmente a superfície. Pontuação do disco do pronoto muito rasa e esparsa. Élitros (fig. 1) com gibosidade arredondada na declividade lateral próxima à epipleura; metade basal com pontos grandes, profundos e próximos, gradualmente mais rasos e mais afastados para os ápices; pubescência não cobre toda a superfície, na base bem esparsa e concentrada em alguns pontos, na metade apical mais densa; superfície muito brilhante nas áreas destituídas de pubescência. Extremidades elitrais arredondadas em conjunto. Fêmures pedunculados e fortemente clavados; pubescência mais alaranjada para o ápice e não recobre toda a superfície femoral. Protíbias e mesotíbias com dentículos no lado interno (40x). Pêlos esbranquiçados, relativamente longos no prosterno, procoxas, mesosterno e mesocoxas. Face inferior do corpo com pubescência esbranquiçada no centro e branco-rósea nos lados.

Comprimento total, 9,0-10,3; comprimento do protórax, 2,1-2,3; maior largura do protórax, 3,0-3,5; comprimento do élitro, 6,0-7,3; largura umeral, 3,9-4,5.

Material-tipo. Holótipo 9, BRASIL, Amazonas: Manaus (Reserva Ducke, $26 \mathrm{~km} \mathrm{NE}$ ), 25.III.1996, J. C. G. Hurtado col., capturado com inseticida em Corythophora alta, Lecythidaceae (INPA). Parátipos: 3 б, 1 , mesmos dados do holótipo (MCNZ, MZSP); 1 , mesma localidade, 14.X.1995, mesmo coletor, mesma planta (INPA); 1 , mesma localidade, 20.III.1996, mesmo coletor, capturado com inseticida em Ecclinusa guianensis Eyma, Sapotaceae (MZSP).

Discussão. Xenofrea fulgida caracteriza-se pelos élitros com tegumento muito brilhante e com grumos esparsos de pubescência amarelo-esbranquiçada (fig. 1) e pelos abundantes dentículos na face interna das mesotíbias. 


\section{Xenofrea albofasciata sp. nov.}

(Fig. 3)

Etimologia. Latim, albus = branco; fasciatus = com banda; alusivo à faixa branca dos élitros.

Fêmea. Tegumento avermelhado; quarto basal dos élitros, uma faixa mediana curva e ápices elitrais, pretos. Escamas (40x) brancas, concentradas numa faixa larga, transversal à frente do meio dos élitros. Cabeça revestida por pubescência esbranquiçada.

Tubérculos anteníferos elevados, distantes entre si. Lobos oculares superiores tão distantes entre si quanto o dobro da largura de um lobo. Lobos oculares inferiores apenas mais longos do que as genas. Antenas com tegumento avermelhado revestido por pubescência esbranquiçada e esparsa. Antenas não atingem o ápice dos élitros. Antenômero III um terço mais longo do que o seguinte; antenômero III e IV em conjunto subiguais em comprimento aos V-X reunidos. Protórax mais largo do que longo com uma gibosidade no meio de cada lado; sem tubérculo lateral próximo à borda anterior. Pronoto regularmente convexo, sem gibosidades, densamente pontuado; escamas (40x) mais concentradas numa faixa estreita, centro-longitudinal. Prosterno com pubescência longa, branca. Escutelo com a região central glabra e margens com escamas brancas. Élitros (fig. 3) densa e profundamente pontuados em toda a superfície; extremidades elitrais arredondadas em conjunto; pubescência branco-amarelada na metade apical. Mesosterno, mesepimeros, metasterno e metepisternos revestidos por escamas brancas. Urosternito $\mathrm{V}$ com pequeno tufo de pêlos pretos, longos, de cada lado, próximo ao ápice. Fêmures gradualmente engrossados para a extremidade. Sulco das mesotíbias no quarto apical.

Comprimento total, 6,3-7,0; comprimento do protórax, 1,4-1,5; maior largura do protórax, 2,0-2,1; comprimento do élitro, 4,6-5,1; largura umeral, 2,7-2,9.

Material-tipo. Holótipo Y, BRASIL, Paraná: Rio Negro, XII.1923, W. Witte col., ex-Coleção Melzer (MZSP). Parátipo ' , Santa Catarina: Seara (Nova Teutônia, $27^{\circ} 11^{\prime}$ S, $52^{\circ} 23^{\prime} \mathrm{W}, 300$ a 500 m), XI.1972, F. Plaumann col. (MZSP).

Discussão. Xenofrea albofasciata distingue-se de X. apicalis Melzer, 1931 e X. lineatipennis Zajciw, 1961 pela presença de faixa larga de escamas brancas concentradas adiante do meio dos élitros; pelo pronoto esparsamente pubescente; pela base dos élitros sem escamas brancas e pelos fêmures gradualmente engrossados para os ápices. Em $X$. apicalis $\mathrm{e} X$. lineatipennis as escamas brancas localizam-se no terço apical dos élitros; o pronoto e a base dos élitros são densamente revestidos por escamas brancas; os fêmures são fortemente pedunculados e clavados.

\section{Hemilophini \\ Sphallonycha irundisa sp. nov.}

(Fig. 9)

Etimologia. Tupi, irundí = quatro; sá = olho; alusivo à divisão ocular .

Macho. Tegumento, em geral, vermelho-alaranjado, revestido por pubescência ferrugínea. Escapo, pedicelo, extremidades basal e apical do antenômero III, metade apical do antenômero VI e antenômeros VII a XI, pretos.

Fronte mais larga do que longa, levemente abaulada. Olhos divididos; lobos oculares superiores tão distantes entre si quanto aproximadamente o triplo da largura de um lobo; lobos oculares inferiores arredondados, mais curtos do que as genas. Antenas, mais 
longas do que o corpo, atingem a extremidade dos élitros aproximadamente no ápice do antenômero VII. Antenômeros III+IV quase tão longos quanto os antenômeros seguintes somados. Franja de pêlos do antenômero III no lado interno com pêlos mais longos do que a largura do artículo. Protórax (fig. 9) mais estreito do que a cabeça e mais constrito na base; lados sem gibosidades. Disco pronotal discretamente elevado. Cada élitro com duas carenas laterais: a interna estende-se do úmero até o terço apical e a externa, separada da interna, inicia-se aproximadamente no meio da interna e ultrapassa-a posteriormente. Uma faixa sutural de pubescência branco-amarelada do escutelo até o meio. Extremidades elitrais subtruncadas com espículo externo. Garras tarsais com dente interno largo, curto, não atinge o meio do externo.

Comprimento total, 6,2; largura da cabeça ao nível dos olhos, 1,8; comprimento do protórax, 1,2; maior largura do protórax. 1,5; comprimento do élitro 4,2; largura umeral, 2,0.

Material-tipo. Holótipo ơ', BRASIL, Amazonas: Manaus (Reserva Ducke, 26 km NE), 8.III.1996, J. C. G. Hurtado col. (coleta com nuvem de inseticida na copa de Ecclinusa guianensis Eyma, Sapotaceae) (INPA).

Discussão. Até o momento, o gênero Sphallonycha Bates, 1881, só era conhecido pela espécie-tipo, S. roseicollis (Bates, 1866) (Monné, 1995). Sphallonycha irundisa difere de $S$. roseicollis por apresentar olhos divididos e faixa sutural estreita de pubescência branco-amarelada que ultrapassa o meio dos élitros. Além disso, S. roseicollis apresenta parte do tegumento corporal preto e, em S. irundisa, o tegumento é inteiramente vermelhoalaranjado.

\section{Apagomerina apicalis sp. nov.}

(Fig. 4)

Etimologia. Latim, apex = ápice; alusivo à ponta preta dos élitros.

Fêmea. Cabeça com tegumento bicolor: preto no meio da fronte e atrás dos olhos e avermelhado nas demais regiões. Antenas, sexto apical dos élitros, esternos torácicos (exceto mesosterno), urosternitos, tíbias e tarsos, pretos. Restante do corpo e fêmures com tegumento alaranjado. Protórax (fig. 4) com gibosidades laterais acentuadas no nível do meio. Centro da base do pronoto com elevação discreta. As partes cefálicas de tegumento alaranjado e o protórax são revestidos por pubescência dourada, visível conforme o ângulo de incidência da luz. Pubescência dos élitros (fig.4) amarelada, relativamente densa, exceto na região de tegumento escuro onde é castanha.

Comprimento total, 9,3; comprimento do protórax, 1,5; maior largura do protórax, 2,0; comprimento dos élitros, 6,6; largura umeral, 2,4.

Material-tipo. Holótipo 9, BRASIL, Santa Catarina: Rio Vermelho, III.1960, Dirings (MZSP).

Discussão. MARTINS \& GALILEO (1996) publicaram uma chave para identificação das onze espécies de Apagomerina. São discriminadas, no item 2, A. flava Martins \& Galileo, 1989 e A. diadela Martins \& Galileo, 1996, que possuem o tegumento dos élitros predominantemente avermelhado. Apagomerina apicalis difere de A. flava pela cabeça preta na maior parte da superfície; pela ponta dos élitros preta e pelo protórax com uma grande gibosidade no meio de cada lado. Em A. flava a cabeça é avermelhada, os élitros são unicolores e as gibosidades laterais do protórax são discretas.

Difere de $A$. diadela, descrita da Venezuela, pelo tegumento alaranjado do protórax que também é unicolor; pelos élitros com sutura concolor e ápices enegrecidos; pelo 

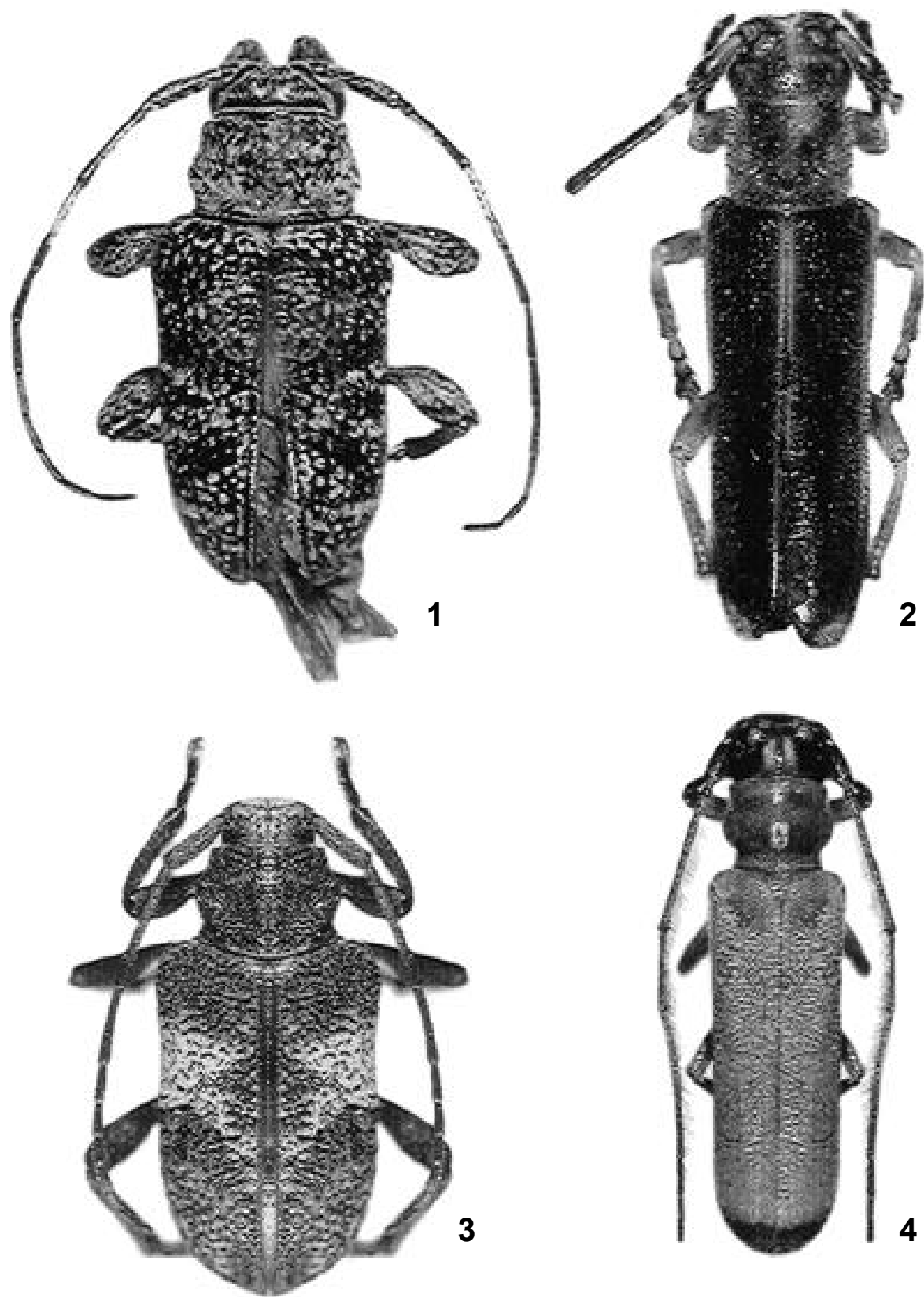

Figs. 1-4. 1, Xenofrea fulgida sp. nov., holótipo 9, comprimento 6,9 mm; 2, Canarana exotica sp. nov., holótipo $\sigma^{\top}$, comprimento $9,6 \mathrm{~mm} ; 3$, Xenofrea albofasciata sp. nov., holótipo 9 , comprimento 7,0 mm; 4, Apagomerina apicalis sp. nov., holótipo 9 , comprimento 9,3 mm. 
protórax fortemente abaulado no meio de cada lado e pelas tíbias e tarsos pretos. Em $A$. diadela o tegumento do protórax é castanho-escuro; a sutura elitral tem pubescência amarelada, os ápices são concolores; os lados do protórax têm gibosidade pouco projetada e as pernas são avermelhadas.

\section{Isomerida paraba sp. nov.}

(Fig. 5)

Etimologia. Tupi, paraba = bicolor; alusivo ao colorido dos élitros.

Fêmea. Fronte e genas com tegumento amarelado revestido por pubescência branca. Vértice, occipício e região atrás dos olhos com tegumento preto. Escapo escurecido na metade basal, avermelhado na metade apical exceto o ápice que é estreitamente preto. Pedicelo com tegumento avermelhado na metade basal e preto na apical. Antenômero III preto no lado superior e amarelado no inferior; antenômero IV inteiramente esbranquiçado, revestido por pêlos pretos, curtos na metade basal; antenômero $\mathrm{V}$ com tegumento e pêlos brancos; antenômero VI branco com pêlos pretos moderadamente esparsos; antenômeros VII a XI com tegumento acastanhado ou castanho-esbranquiçado recoberto por pêlos pretos. Antenômero III com pêlos esparsos na margem interna. Escapo subigual em comprimento ao antenômero IV e um quarto mais curto do que o III. Protórax com tegumento alaranjado, revestido por pubescência branca, exceto em área centro-dorsal de tegumento preto. Lados do protórax com pubescência branca, compacta. Tegumento elitral bicolor (fig. 6): no dorso, amarelo-enfumaçado e, nos lados, castanho-escuro. Cada élitro com uma faixa de pubescência branca, compacta, paralela à sutura, que se estende até o quarto apical. Carena umeral bem marcada até o quarto apical; carena externa pouco notável, paralela à umeral. Bases das epipleuras com tegumento amarelado. Extremidades elitrais obliquamente truncadas com espículo externo. Fêmures amarelados; tíbias amareladas com a face externa preta; tarsos amarelados. Esternos torácicos e urosternitos com tegumento escuro. Faixa de pubescência branca compacta na metade dorsal dos mesepisternos, mesepimeros, metepisternos, ângulos posterior e externo do metasterno, metacoxas e uma faixa longitudinal, larga, no urosternito I; urosternito IV quase inteiramente recoberto por pubescência branca, compacta, exceto estreita área central.

Comprimento total, 9,0; comprimento do protórax, 1,1; maior largura do protórax, 2,1; comprimento do élitro, 6,5; largura umeral, 2,8 .

Material-tipo. Holótipo Y, BRASIL, Amazonas: Manaus (Reserva Ducke, 26 km NE), XII.1995, M. G. V. Barbosa col., malaise (INPA).

Discussão. O gênero Isomerida Bates, 1866 foi revisto por GaliLEo \& Martins (1996) e I. paraba, pela presença de faixa longitudinal de pubescência branca nos élitros, assemelha-se à I. vittata (Pascoe, 1858), I. lanifica (Germar, 1824), I. sororcula Galileo \& Martins, 1996, I. ibitira Martins \& Galileo 1992 e I. lineata Bates, 1872. Difere de todas pelo seguinte conjunto de caracteres: coloração e pilosidade antenal; colorido do protórax e dos élitros; carena externa dos élitros pouco visível e distribuição da pubescência branca compacta na face ventral do corpo. 

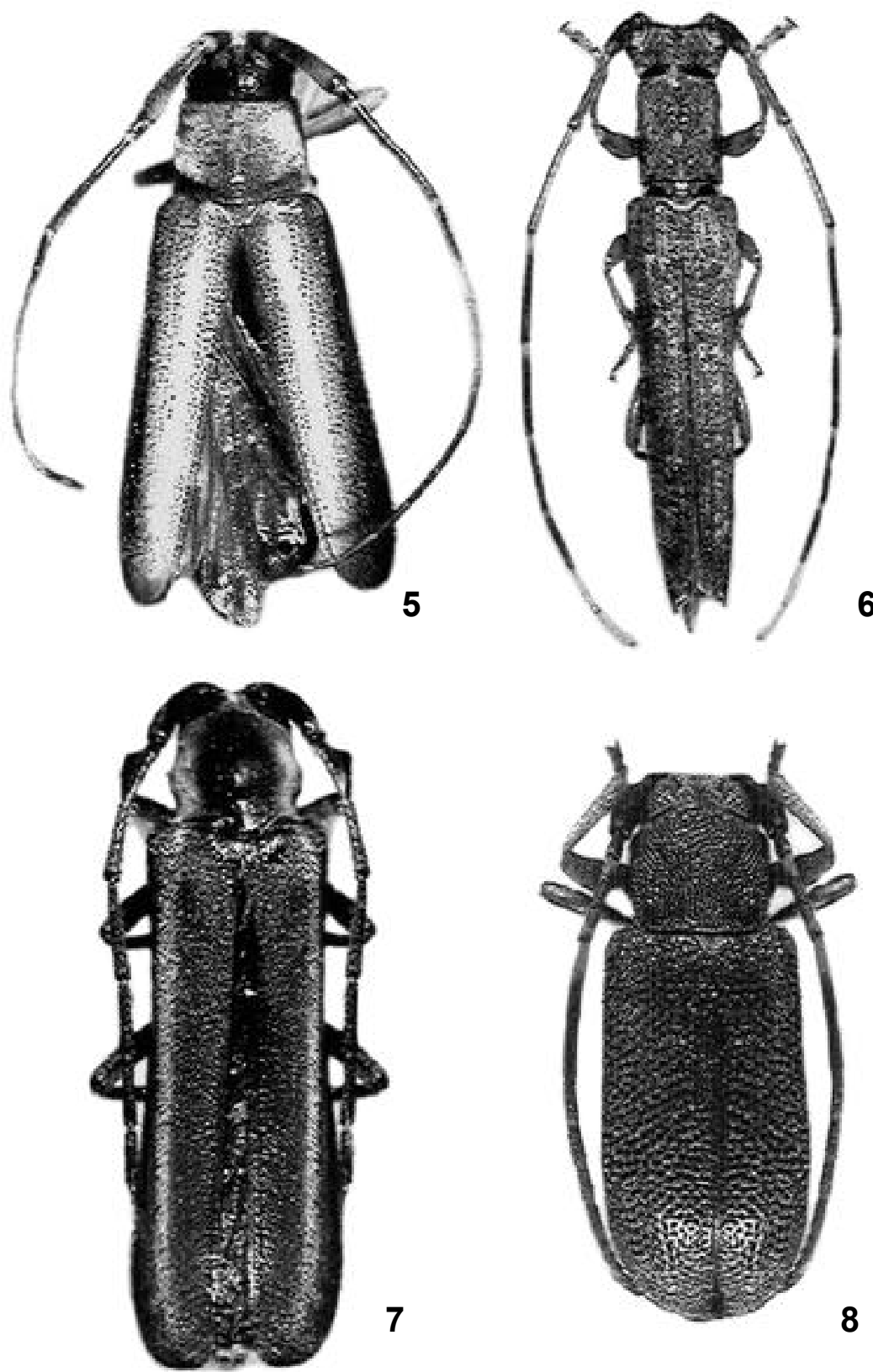

Figs. 5-8. 5, Isomerida paraba sp. nov., holótipo 9 , comprimento 9,0 mm; 6, Nyctonympha carioca sp. nov., holótipo $\sigma^{\prime}$, comprimento $8,5 \mathrm{~mm} ; 7$, Isomerida santamarta sp. nov., holótipo 9 , comprimento $13,7 \mathrm{~mm} ; 8$, Euryestola castanea sp. nov., holótipo $\sigma^{-2}$, comprimento, 3,6 mm. 


\section{Isomerida santamarta sp. nov.}

(Fig. 7)

Etimologia. Epíteto alusivo à localidade-tipo.

Fêmea. Tegumento preto, exceto lados do protórax, procoxas, lados do mesosterno, metepisterno, trocanteres, meso- e metacoxas e áreas nos urosternitos III e IV onde o tegumento é alaranjado ou amarelado. Cabeça com pequena área longitudinal entre os tubérculos anteníferos revestida por pubescência branca. Extremo basal dos antenômeros IV a VIII com tegumento amarelado. Antenas quase atingem a extremidade elitral. Franja de pêlos na margem interna dos flagelômeros basais (III-VIII) esparsa. Escapo com quase a metade do comprimento do antenômero III. Antenômero III um terço mais longo do que o IV. Protórax cilíndrico com constrição basal acentuada e gibosidade lateral no nível do meio. Disco pronotal levemente giboso no centro. Cada élitro (fig. 7), com faixa de pêlos esbranquiçados, longitudinal, estreita, junto à carena umeral e prolongada até quase o ápice. Élitros levemente expandidos para fora, logo depois do meio; extremidades individualmente arredondadas. Urosternitos III e IV com manchas de pubescência compacta, branca que não atingem o meio nem a margem do urosternito.

Comprimento total, 13,7; comprimento do protórax, 2,2; maior largura do protórax, 2,6; comprimento do élitro, 10,4; largura umeral, 3,7 .

Material-tipo. Holótipo ९, COLÔMBIA, Magdalena: San Lorenzo (41 km S de Santa Marta, 7.000 pés), V.1973, Howden \& Campbell col. (CMNO)

Discussão. Isomerida santamarta apresenta caracteres de Isomerida, mas o aspecto geral lembra o de Hilaroleopsis Lane, 1970, pela fronte estreita, pelos élitros levemente expandidos lateralmente na metade apical, pelas extremidades arredondadas e pela sutura metasternal profunda na parte posterior. Distingue-se por apresentar a carena umeral e a lateral contíguas e, portanto, situa-se mais apropriadamente em Isomerida, muito embora os antenômeros basais não apresentem franja compacta de pêlos. Por esse caracter, assemelha-se a I. separata, conhecida do Equador, mas difere pelo colorido corporal, pela faixa de pubescência branca em cada élitro e pelas manchas pubescentes nos urosternitos III e IV das fêmeas.

\section{Canarana exotica sp. nov.}

(Fig. 2)

Etimologia. Grego, exotikos = exótico, estrangeiro; alusivo ao aspecto geral.

Macho. Cabeça vermelho-alaranjada; tubérculos anteníferos e regiões atrás dos olhos pretos. Revestimento de pubescência esbranquiçada sobre as áreas de tegumento vermelho-alaranjado. Antenas tão longas quanto o corpo; todos os artículos, inclusive o escapo, com base avermelhada ou amarelada e pretos no restante; com pubescência preta; franja de pêlos longos, pretos na margem interna do antenômero III; antenômero III com o dobro do comprimento do IV. Protórax constrito na base com gibosidade lateral pronunciada; vermelho-alaranjado com faixas longitudinais pretas: duas largas de cada lado do pronoto, juntam-se na base; uma nos lados do protórax, acima das procoxas. Pontuação pronotal muito esparsa. Pubescência das partes laterais do protórax relativamente longa e espessa. Élitros (fig. 2) pretos com os frisos sutural e marginal e a 


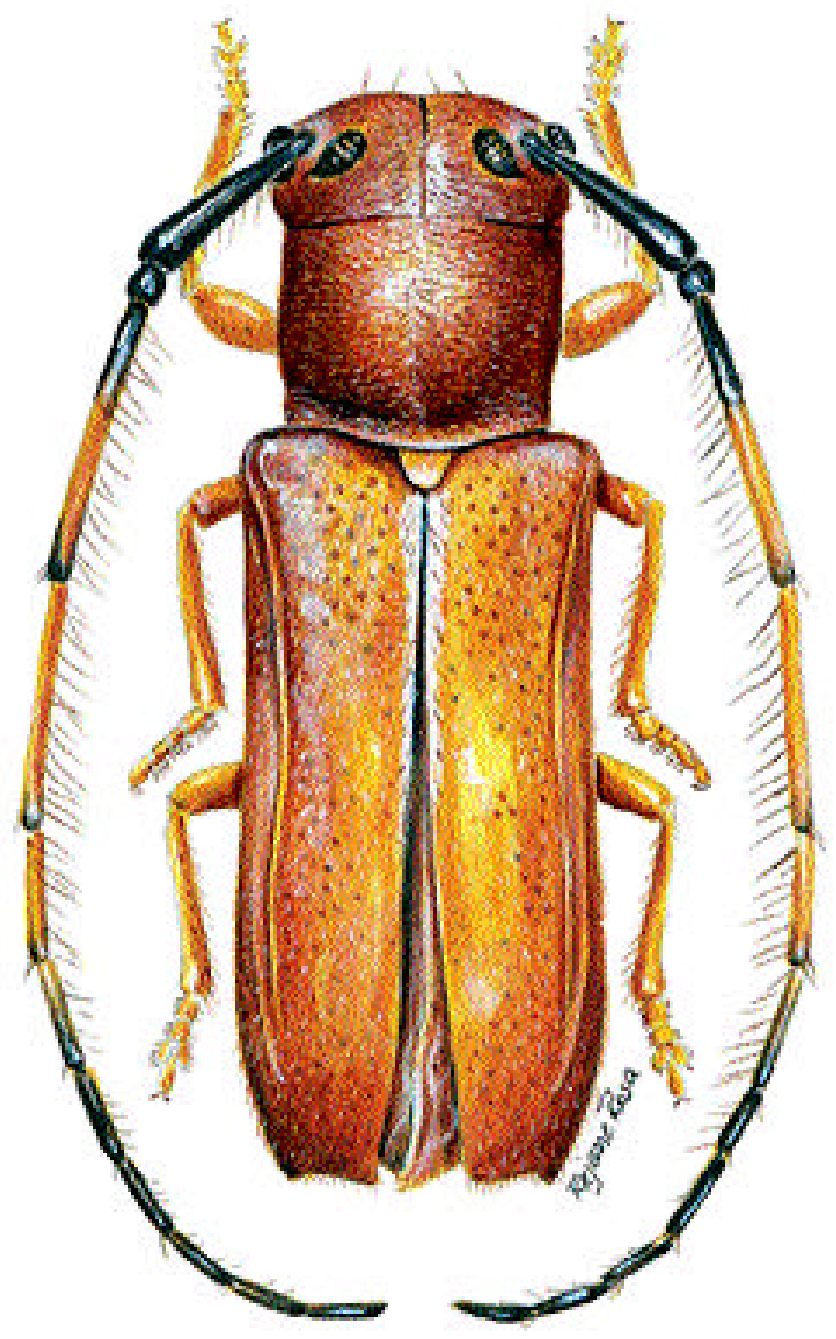

Fig. 9. Sphallonycha irundisa sp. nov., holótipo o', comprimento $6,2 \mathrm{~mm}$. 
carena umeral, em toda a extensão, amarelados. Extremidades transversalmente truncadas. Esternos mesotorácicos avermelhados. Esternos metatorácicos e urosternitos I a III, acastanhados. Profêmures com os dois terços basais amarelados e o ápice castanho. Mesofêmures com a metade basal amarelada e a apical castanha; metafêmures com o terço basal amarelado e os dois terços apicais castanhos. Tíbias acastanhadas com as bases amareladas. Tarsos acastanhados; bases dos tarsômeros I e II amareladas.

Dimensões. Comprimento total, 9,6; comprimento do protórax 1,8; maior largura do protórax, 2,3; constrição basal do protórax 1,8; comprimento do élitro, 6,8; largura umeral, 2,7 .

Material-tipo. Holótipo ơ, EQUADOR, Pichincha: Santo Domingo (Río Palenque, 4,7 km S de Santo Domingo, 700 pés), 22.II.1976, H. \& A. Howden col. (CMNO).

Discussão. Canarana exotica caracteriza-se pelo seguinte conjunto de caracteres: cabeça e protórax bicolores; antenas com os artículos amarelados na base; élitros pretos com frisos sutural e marginal e carena umeral, amarelados; pernas bicolores; ápice dos élitros truncados e desarmados.

\section{Falsamblesthiini}

\section{Nyctonympha carioca sp. nov.}

(Fig. 6)

Etimologia. Tupi, karíoka = casa do branco; carioca, natural do Rio de Janeiro; alusivo à localidade-tipo.

Macho. Colorido geral vermelho-acastanhado. Antenas castanhas com a base dos antenômeros IV a VIII amarelada e os antenômeros IX e X inteiramente amarelados (XI, falta). Pernas avermelhadas; fêmures com anel central castanho pouco evidente. Fronte e região entre os tubérculos anteníferos com pubescência branca. Vértice profundamente pontuado. Lobos superiores dos olhos com seis fileiras de omatídios, pouco mais próximos entre si do que a largura de um lobo. Mandíbulas não-entalhadas no ápice. Tubérculos laterais do protórax (fig. 6) diminutos. Disco pronotal densa e profundamente pontuado. Pubescência esbranquiçada, esparsa, em toda a superfície exceto em pequena mancha central de pubescência branca compacta. Partes laterais do protórax com duas faixas longitudinais de pubescência branca. Extremidades elitrais (fig. 6) cortadas em curva com espinho externo. Pontos do dorso elitral organizados em três fileiras longitudinais no meio de cada élitro; declividade lateral da metade apical com pontos dispostos em continuação aos das fileiras da metade anterior, estendem-se até o sexto apical. Pubescência esbranquiçada, muito esparsa e mais concentrada em pequenas manchas pouco aparentes. Mesepimeros, lados do metasterno e lados dos urosternitos I a IV com pontos pequenos, pouco densos.

Comprimento total, 8,5; comprimento do protórax, 1,5; maior largura do protórax, 1,4; comprimento dos élitros 6,0; largura umeral 1,5.

Material-tipo. Holótipo ơ, BRASIL, Rio de Janeiro: Rio de Janeiro, X, Acc. 2966 (CMNH).

Discussão. Nyctonympha carioca assemelha-se a N. andersoni Martins \& Galileo, 1992 e N. genieri Martins \& Galileo, 1992, respectivamente, da Colômbia e do Equador (Martins \& Galileo, 1992), por apresentar os mesepimeros e urosternitos pontuados e os fêmures uniformemente pubescentes. Distingue-se de ambas pela presença de pubescência branca, densa entre os tubérculos anteníferos; pequena mancha de 
pubescência branca no centro do pronoto e antenômeros IX-X com tegumento amarelado.

\section{Calliini \\ Euryestola castanea sp. nov.}

(Fig. 8)

Etimologia. Latim, castanea = castanho; alusivo à coloração.

Macho. Tegumento castanho-avermelhado; élitros, bases das coxas, tíbias e tarsos, castanho-amarelados. Antenas castanho-escuras com estreito anel basal no antenômero III e metade basal do IV, amarelados. Pubescência amarelada, esparsa, uniformemente distribuída em todo corpo. Pontuação grossa, densa, uniforme em todo o corpo. Fronte mais larga que longa; sutura coronal aprofundada. Olhos desenvolvidos; lobos oculares superiores com seis fileiras de omatídios e separados entre si por distância menor que a largura de um lobo. Lobos oculares inferiores ocupam todo o lado da cabeça. Antenas atingem as extremidades elitrais. Antenômero III mais longo do que o seguinte. Lados do protórax com gibosidade pouco manifesta situada pouco atrás do meio. Disco pronotal com três gibosidades apenas indicadas. Élitros (fig. 8) sem manchas de pubescência esbranquiçada. Distância entre pontos nos élitros menor que o diâmetro de um ponto. Cerdas curtas inseridas na borda anterior de cada ponto. Fêmures gradualmente engrossados para a extremidade.

Comprimento total, 3,6; comprimento do protórax, 0,8; maior largura do protórax, 1,$1 ;$ comprimento do élitro, 2,1 ; largura umeral, 1,4 .

Material-tipo. Holótipo ơ', BRASIL, Amazonas: Manaus (Reserva Ducke, 26 km NE de Manaus), 1.IV.1996, J. C. G. Hurtado col., coletado com inseticida na copa de Corythophora alta, Lecythidaceae (INPA).

Discussão. O gênero Euryestola foi revisto por Galileo \& Martins (1997). E. castanea separa-se prontamente das demais espécies pela coloração das antenas, onde apenas um estreito anel basal no antenômero III e a metade basal do antenômero IV são amarelados. Nas demais espécies as antenas apresentam as bases de vários artículos amareladas (GALILEO \& MARTINs,1997, figs. 1-4). Além disso, os élitros de E. castanea não têm pubescência esbranquiçada.

Agradecimentos. Ao CNPq, pela concessão de bolsas de pesquisa aos autores. À desenhista Rejane Rosa, MCNZ, pela confecção da arte final de Sphallonycha irundisa; ao Jorge Luiz Dutra Soledar, bolsista de Iniciação Científica, FAPERGS, pela execução das fotografias obtidas por programa Leica EWF-2100.

\section{REFERÊNCIAS BIBLIOGRÁFICAS}

Galileo, M. H. M. \& Martins, U. R. 1996. Revisão do gênero Isomerida Bates, 1866 (Coleoptera, Cerambycidae, Lamiinae, Hemilophini). Papéis Avuls Zool., São Paulo, 39(12): 231-248.

_- 1997. Revisão do gênero Euryestola Breuning, 1940 (Coleoptera, Cerambycidae, Lamiini, Calliini). Papéis Avuls Zool., São Paulo, 40(7): 127-136.

_. 1999. Sobre espécies de Lamiinae (Coleoptera, Cerambycidae) da Colômbia e do Brasil com garras tarsais divaricadas. Papéis Avuls Zool., São Paulo, 41(6): 85-106.

Martins, U. R. \& Galileo, M. H. M. 1992. Neotropical Cerambycidae (Coleoptera) primarily in the Canadian Museum of Nature, Ottawa. I. Falsamblesthiini (Lamiinae). Insecta Mundi, Gainesville 6(2): $101-108$.

__. 1996. Transferência de gêneros de Aerenicini para Hemilophini, novos táxons e chave para as 
espécies de Apagomerina Gilmour, 1962 (Coleoptera, Cerambycidae, Lamiinae). Revta bras. Ent., São Paulo, 40(1): 21-24.

MonnÉ, M. A. 1994. Catalogue of the Cerambycidae (Coleoptera) of the Western Hemisphere. Part XVII. São Paulo, Sociedade Brasileira de Entomologia. 110 p.

1995. Catalogue of the Cerambycidae (Coleoptera) of the Western Hemisphere. Part

XX. São Paulo, Sociedade Brasileira de Entomologia, 120 p. 